\title{
Preliminary Tests of a Kerma-Area Product (KAP) Meter to Be Used as a Monitor Chamber in a Conventional Diagnostic X Ray System
}

\author{
Eduardo Correa1, Regina Medeiros' ${ }^{1}$, Maria da Penha Potiens' ${ }^{1}$, Vitor Vivolo, \\ Nathalia Costa ${ }^{1}$, Camila Murata ${ }^{2}$, Cristina Kikuti ${ }^{2}$ \\ ${ }^{1}$ Instituto de Pesquisas Energéticas e Nucleares (IPEN-CNEN), Universityof São Paulo (USP), São Paulo, Brazil \\ ${ }^{2}$ Federal University of Sao Paulo (UNIFESP), São Paulo, Brazil \\ Email: educorrea1905@gmail.com
}

Received 1 December 2014; accepted 24 March 2015; published 27 March 2015

Copyright (C) 2015 by authors and Scientific Research Publishing Inc.

This work is licensed under the Creative Commons Attribution International License (CC BY). http://creativecommons.org/licenses/by/4.0/

(c) (i) Open Access

\section{Abstract}

This study presents the results of the preliminary tests performed using a kerma-area product (KAP) meter in order to verify its usefulness as a monitor chamber in a clinical $X$ ray system, which will be used in ionization chambers' quality control program. The tests performed were repeatability, surface measurement uniformity, linearity with tube current, measurement variation changing the distance and field size, KAP chamber radiation attenuation, and energy dependence. The KAP meter has presented a good repeatability (a maximum variation of $0.4 \%$ ); its surface has a homogeneous response (a maximum variation of 1.0\% among the different irradiated regions); the response is linear with the tube current and the variation of the $\boldsymbol{P}_{K A}$ along the distance is less than $3.43 \%$. On the other hand, the results obtained for chamber attenuation and energy dependence show that some corrections must be applied when the measurements are made. The results have shown a good performance of the KAP meter, confirming that it is possible to use this instrument as a monitor chamber. However, it is important to highlight that some correction factors for energy dependence and chamber radiation attenuation must be considered.

\section{Keywords}

KAP Meter, Quality Control, Diagnostic Radiology, Monitor Chamber

\section{Introduction}

In radiation meters calibration laboratories are common to find a monitor chamber in calibration setup, which is

How to cite this paper: Correa, E., Medeiros, R., da Penha Potiens, M., Vivolo, V., Costa, N., Murata, C. and Kikuti, C. (2015) Preliminary Tests of a Kerma-Area Product (KAP) Meter to Be Used as a Monitor Chamber in a Conventional Diagnostic X Ray System. Journal of Modern Physics, 6, 483-489. http://dx.doi.org/10.4236/jmp.2015.64052 
used for a real-time radiation beam monitoring. When it is plugged to appropriate software, it is possible to obtain information about exposure time, accumulated air-kerma and air-kerma rate, and also identify a possible beam intensity variation. This equipment is important in standardization dosimetry laboratories, which must always work with reduced uncertainties.

The Instruments Calibration Laboratory (LCI) of the Instituto de Pesquisas Energéticas e Nucleares (IPEN/ CNEN-SP) has a PTW monitor chamber (reference chamber) installed on its X ray calibration system.

The radiation physics and hygiene coordination of the Federal University of São Paulo (CFHR-UNIFESP) have a laboratory (LEMADIM) with a clinical $\mathrm{X}$ ray system used to perform dosimetry and image techniques research. Due to the importance of this equipment for the CFHR researches, and the financial difficulty in buying a specific monitor chamber, it is proposed to use the KAP meter as a monitor chamber, since it is already used to monitor the $\mathrm{X}$ ray beam in interventional equipments in order to estimate the patient dose [1]. The proposal of using the KAP meter in the conventional system as a monitor chamber is to reduce measurement uncertainties. This will be useful to verify the behavior of radiation detectors that are used in the diagnostic radiology energy range.

The KAP performance tests were made at LCI and were based on the International Eletrotechnical Commission (IEC) standard IEC 60580 [2] and IEC 61674 [3]. The LCI reference ionization chamber has traceability to the German Primary Dosimetry Laboratory Physikalisch-Technische Bundesanstalt (PTB).

The aim of this study was to verify if the KAP meter could be used in radiation beam monitoring at the LEMADIM clinical $\mathrm{X}$ ray system in order to achieve the uncertainties required by IEC.

In this study, the recommended nomenclatures were used, presented by the International Atomic Energy Agency (IAEA) [4]: KAP (air-kerma area product) meter instead of DAP (dose area product) meter for the instrument, and $P_{K A}$ for the quantity.

\section{Materials and Methods}

\subsection{Materials}

A PTW KAP meter, Diamentor E2 model (Figure 1), which consists of a reading module connected to a square transmission ionization chamber of $141 \mathrm{~mm}$ width and equivalent attenuation of $0.2 \mathrm{mmAl}$, was tested.

Due to the fact that this is a non-sealed chamber, all the measurements must be corrected for environmental conditions (temperature and pressure), using Equation (1):

$$
F_{t, p}=\left(\frac{101.3}{P}\right) \cdot\left(\frac{T+273.15}{293.15}\right)
$$

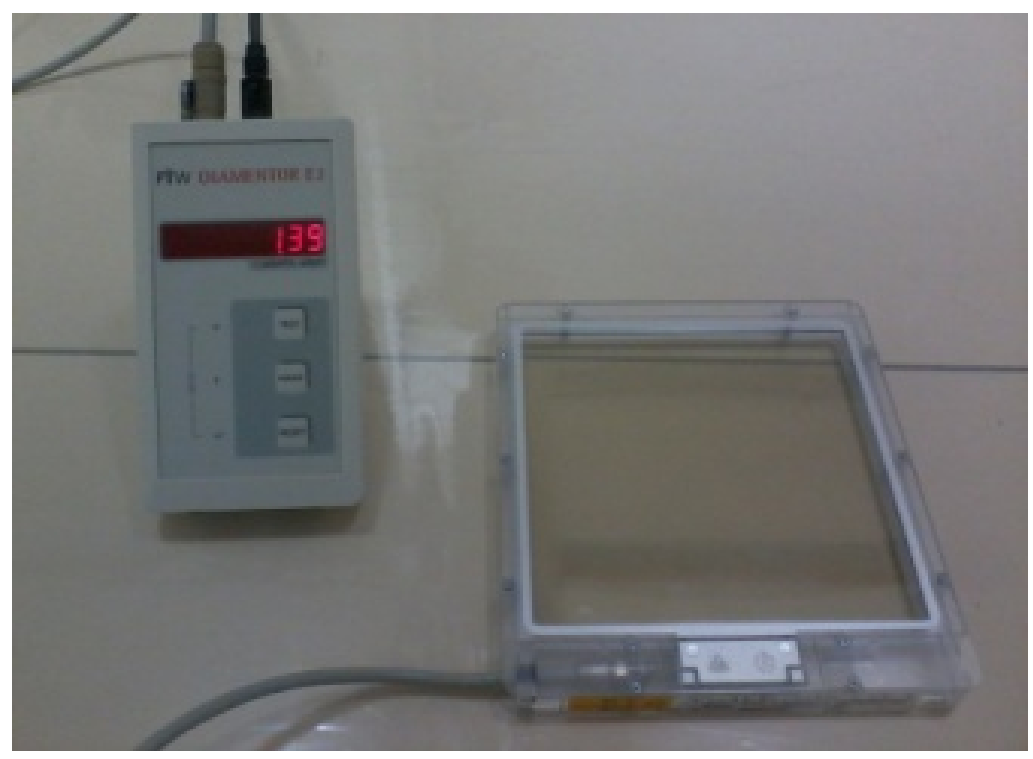

Figure 1. The KAP meter. Left: the reading module. Right: the square chamber. 
where $P$ and $T$ are, respectively, the measured pressure (in $\mathrm{kPa}$ ) and temperature $\left(\right.$ in ${ }^{\circ} \mathrm{C}$ ).

The tests were made using an industrial $X$ ray system Pantak/Seifert (Figure 2(a)), which can generate voltages up to $160 \mathrm{kV}$. This system has the mammography [5] and the RQR [6] radiation qualities established, according to the International Electrotechnical Commission (IEC) standard IEC 61267 [7]. It has also been recently used as reference for the establishment of an in situ KAP meter calibration methodology [8]. The Radcal ionization chamber, RC6 model (Figure 2(b)) was used to obtain the reference air-kerma value to determine the KAP meter energy dependence. It was calibrated at the German Primary Dosimetry Laboratory PhysikalischTechnische Bundesanstalt (PTB).

The air-kerma was obtained using Equation (2).

$$
K=L_{C} \cdot N_{k} \cdot k_{Q}
$$

where $L_{C}$ is the ionization chamber measurement, corrected for environmental conditions, $N_{k}$ is the chamber calibration coefficient and $k_{Q}$ is the radiation quality coefficient [4], which indicates the instrument energy dependence.

\subsection{Methodology}

The tests were made using the reference radiation quality for radiation diagnostic, RQR-5 (70 kV), except repeatability, linearity and energy dependence.

\subsubsection{Repeatability}

The International Vocabulary of Metrology [9] defines the repeatability as a measurement precision test made under a set of repeatability conditions of measurement in a short period of time. These conditions include the same measurement procedure, same measuring system, same operator, same operating conditions and same location.

A ${ }^{90} \mathrm{Sr}+{ }^{90} \mathrm{Y}$ source was positioned at the center of the KAP meter. Ten measurements were taken, and the procedure was repeated for both chamber sides.

\subsubsection{Surface Uniformity}

The objective of this test was to verify if KAP response depends or not on the surface region that is being irradiated. The chamber was placed about $55 \mathrm{~cm}$ from the focal spot, its surface was divided into five regions (Figure 3 ) and each one was irradiated by a collimated $X$ ray beam.

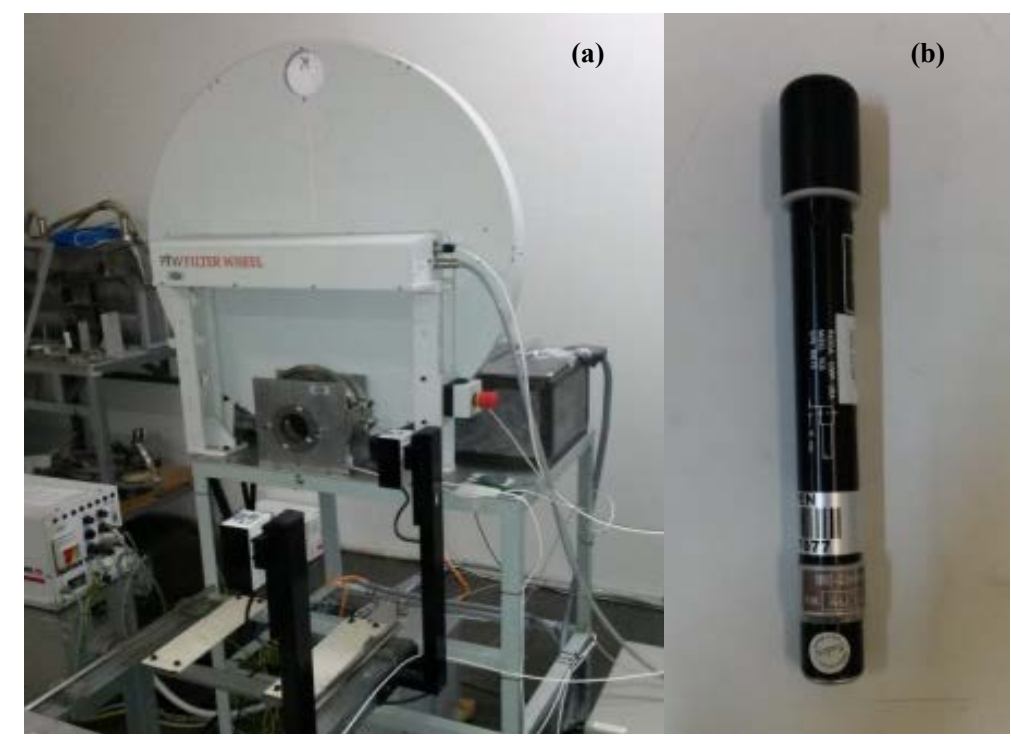

Figure 2. (a) The X ray system Pantak/Seifert, used for the KAP meter tests. (b) The ionizing chamber Radcal, RC6 model, used as reference in diagnostic radiology calibration beams. 


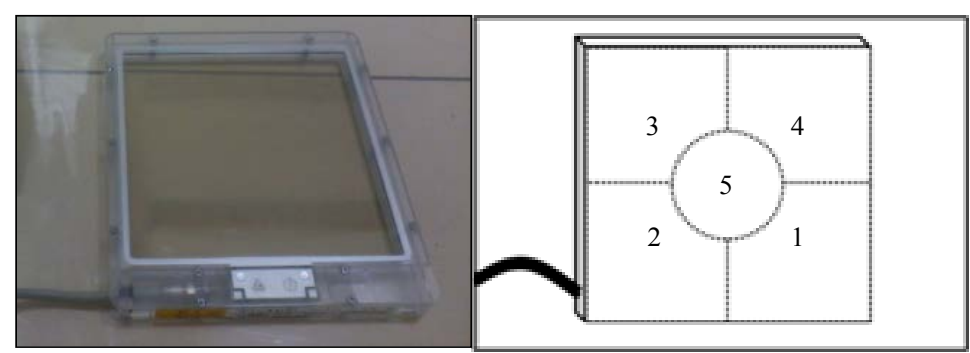

Figure 3. The five regions in which the KAP chamber was divided.

\subsubsection{Linearity with the Tube Current}

This test was made to verify if KAP meter measurement increases linearly with the tube current. A voltage value was established and current was gradually increased. The four voltages recommended by the standard IEC 60580 [2] for instruments calibration in diagnostic radiology $(50 \mathrm{kV}, 70 \mathrm{kV}, 100 \mathrm{kV}$ and $150 \mathrm{kV})$ were used. For each value of current 10 measurements were taken.

\subsubsection{Kerma-Area Product Variation along the Distance}

The major differential of the KAP meter is its capacity to measure the kerma-area product, which should be constant along the distance between the chamber and the $\mathrm{X}$ ray tube. In order to verify this characteristic the KAP chamber has been moved from $50 \mathrm{~cm}$ to $100 \mathrm{~cm}$ away from the $\mathrm{X}$ ray focal spot, keeping the apertures. This test was made using two circular apertures: $50 \mathrm{~mm}$ and $17 \mathrm{~mm}$ diameter.

\subsubsection{KAP Chamber Radiation Attenuation}

This test was made to verify how much the KAP chamber attenuates the radiation beam. The beam intensity has been measured using the reference ionization chamber RC6, which was placed one meter away the focal spot with and without the KAP chamber as monitor chamber.

\subsubsection{Energy Dependence}

To determine the KAP meter energy dependence it was necessary to obtain the calibration coefficient $N_{P_{K A}}$ for each radiation quality $Q$, using Equation (3) [4]:

$$
N_{P_{K A}, Q}=\frac{\dot{K} A\left(\frac{d_{r}}{d_{a}}\right)^{2}}{\dot{M}_{K A P} k_{T P}^{K A P}}
$$

where $k_{T P}^{K A P}$ isair density correction applied to reading rate $\dot{M}_{K A P}$ of the KAP meter.

Reference air-kerma rate $\dot{K}$ was obtained using the reference chamber placed at a distance $d_{r}=100 \mathrm{~cm}$ from the focal spot. A square aperture with a width of $6 \mathrm{~cm}$, with a cross-sectional area $A$ of $36 \mathrm{~cm}^{2}$, was placed at distance $d_{a}=95 \mathrm{~cm}$ from the focal spot.

Calibration coefficients were normalized for the reference quality RQR-5, thereby obtaining the $k_{Q}$ value.

\section{Results}

\subsection{Repeatability}

In repeatability tests the KAP meter presented a maximum variation of $0.37 \%$ (Table 1 ). This result is in accordance with the international standard [3].

It is possible to note that the KAP meter is a very stable instrument, but there is a measurement difference of around $2.5 \%$ between the two sides of the chamber. There is no technical information about this phenomenon in the KAP meter user manual suggesting that it might be a characteristic of this instrument.

\subsection{Uniformity Test}

Results for the uniformity test are shown in Table 2. 


\subsection{Linearity with the Tube Current}

Results show that the KAP meter presents a linear response with the current (Figure 4). This linear response fits for the four qualities with a $R^{2}=1$.

\subsection{Kerma-Area Product Variation along the Distance}

Results for this test are shown in Table 3.

Table 1. Repeatability test results for both sides of the KAP chamber.

\begin{tabular}{lll}
\hline & SIDE 1 & SIDE 2 \\
\hline Mean $\boldsymbol{P}_{K A}\left(\boldsymbol{\mu G y} \cdot \mathbf{m}^{2}\right)$ & $2.27(4)$ & $2.33(5)$ \\
\hline
\end{tabular}

Table 2. Results of the measurement uniformity test. The column "variation from the mean PKA" presents the variation of each value when compared with the mean value.

\begin{tabular}{ccc}
$\begin{array}{c}\text { KAP meter } \\
\text { Irradiated area }\end{array}$ & $\begin{array}{c}\boldsymbol{P}_{\boldsymbol{K A}} \\
\left(\mathbf{m G y} \cdot \mathbf{m}^{\mathbf{2}}\right)\end{array}$ & $\begin{array}{c}\text { Variation from the } \\
\text { mean } \boldsymbol{P}_{\boldsymbol{K A}}\left(\mathbf{1 0} \mathbf{0}^{-\mathbf{2}} \mathbf{)}\right)\end{array}$ \\
\hline $\mathbf{1}$ & $14.44(30)$ & $97.90(99)$ \\
$\mathbf{2}$ & $14.33(25)$ & $20.98(33)$ \\
$\mathbf{3}$ & $14.16(15)$ & $-97.90(99)$ \\
$\mathbf{4}$ & $14.29(29)$ & $-6.99(10)$ \\
$\mathbf{5}$ & $14.28(20)$ & $-14.99(11)$ \\
\hline
\end{tabular}

Table 3. $P_{K A}$ variation when the distance is increased from $50 \mathrm{~cm}$ to $100 \mathrm{~cm}$, for both apertures.

\begin{tabular}{lccrr}
\multicolumn{1}{c}{ Aperture diameter $(\mathrm{mm})$} & \multicolumn{2}{c}{$50.8(1)$} & \multicolumn{2}{c}{$17.0(1)$} \\
\hline $\begin{array}{l}\text { KAP chamber distance from the } \\
\text { focal spot }(\mathrm{cm})\end{array}$ & $100.0(5)$ & $50.0(3)$ & $100.0(5)$ & $50.0(3)$ \\
Kerma-area product, $P_{K A}\left(\mu \mathrm{Gy} \cdot \mathrm{m}^{2}\right)$ & $125.84(3.10)$ & $127.83(2.98)$ & $13.76(40)$ & $14.25(42)$ \\
Variation (\%) & \multicolumn{2}{c}{$1.57(5)$} & $3.43(11)$ \\
\hline
\end{tabular}

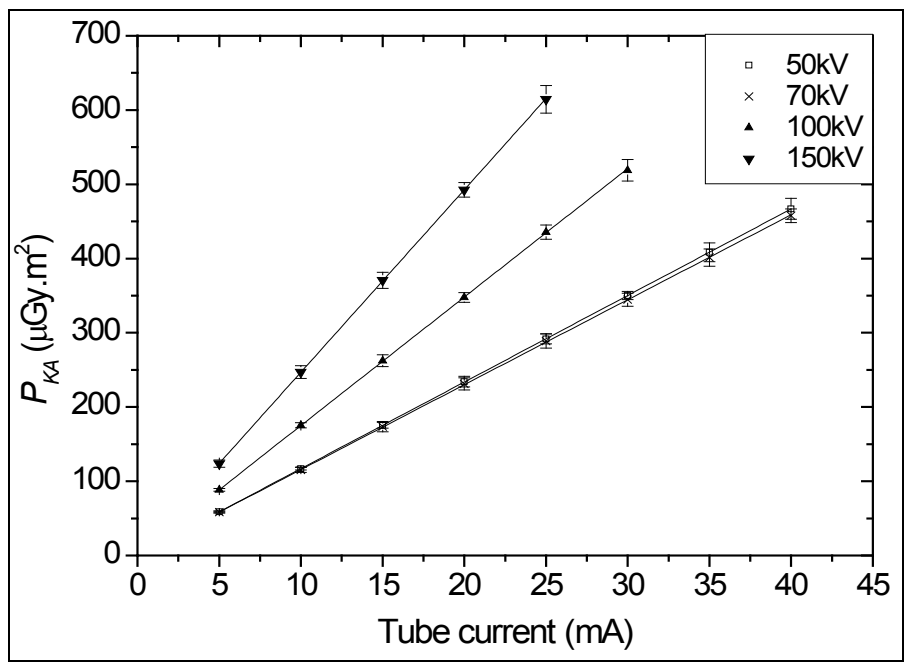

Figure 4. KAP meter response curves with the tube current. 
The maximum variation for the $P_{K A}$ was of $3.43 \%$, when the distance was increased from $50 \mathrm{~cm}$ to $100 \mathrm{~cm}$. The standard IEC 60580 [2] does not present any limits for this test. Although considering that the limits normally applied to instruments used in diagnostic radiology are around 5\% to $10 \%$ [3], it is possible to affirm that this variation will not compromise the measurements.

\subsection{KAP Chamber Radiation Attenuation}

When the monitor chamber was replaced by the KAP chamber it was noticed an attenuation that varied from $11.0 \%$ to $17.7 \%$, depending on the quality (Table 4 ).

Results show a correction is necessary for each quality, since the attenuation caused by the KAP chamber is not constant.

\subsection{Energy Dependence}

Result for the KAP meter energy dependence, for $N_{P_{K A}}=3.47 \mathrm{E}-07 \mathrm{~Gy} / \mathrm{mGy}$, is shown in Table 5 .

The uncertainty for the product $N_{k} \times k_{Q}$ is $3.5 \%$. Results show that the KAP meter energy dependence reached values of up to $25 \%$, which is greater than the $8 \%$ required by IEC 60580 [2]. Other researchers showed that a great variation of calibration coefficient is common in this kind of instrument [10], and much higher than the Patient Dose Calibrator (PDC), equipment used as reference forkerma-area product measurement [11], even when the PDC is used out of it energy range (mammography) [12]. However, according to Toroi et al, the limit of $8 \%$ is reached when calibration for the $\mathrm{X}$ ray beam transmitted through the chamber is considered [10].

It is also important to highlight that these tests were made using the new RQR qualities [7], and the limit presented by IEC 60580 [2] is based on the old RQR qualities [13].

\section{Conclusions}

Results showed a good performance of the KAP meter. This equipment has presented stable and accurate measurements, surface uniformity, linearity with tube current and small $P_{K A}$ variation along the distance.

The energy dependence verified was much higher than the $8 \%$ required by international standards. Previous studies have shown that this behavior is common in this kind of instrument. However, an IEC 60580 standard review, considering the new RQR qualities, may be necessary.

Radiation beam attenuation caused by the KAP chamber was of up to $17.7 \%$, and this value was different for each quality, which indicated that a correction factor must be applied to each measurement.

Table 4. Attenuation caused by the KAP chamber in the different diagnostic radiology qualities.

\begin{tabular}{cccc}
\hline Radiation quality & Voltage $(\mathrm{kV})$ & Additional filtration $(\mathrm{mmAl})$ & Attenuation $(\%)$ \\
\hline RQR 3 & 50 & 2.4 & $17.7(5)$ \\
RQR 5 & 70 & 2.8 & $15.3(4)$ \\
RQR 8 & 100 & 3.2 & $13.1(4)$ \\
RQR 10 & 150 & 4.2 & $11.0(3)$ \\
\hline
\end{tabular}

Table 5. $k_{Q}$ values for the KAP meter, for $N_{P_{K A}}=3.47 \mathrm{E}-07 \mathrm{~Gy} / \mathrm{mGy}$. The uncertainty for the product $N_{k} \times k_{Q}$ is $3.5 \%$.

\begin{tabular}{ccc}
\hline Radiation & Tube voltage & $k_{Q}$ \\
\hline Quality & $(\mathrm{kV})$ & 0.971 \\
RQR 3 & 50 & 1.000 \\
RQR 5 & 70 & 1.147 \\
RQR 8 & 100 & 1.252 \\
\hline RQR 10 & 150 & \\
\hline
\end{tabular}


In general, it is possible to use the KAP meter as a monitor chamber since the energy dependence and attenuation for different beam qualities are well known and re-checked periodically.

\section{Acknowledgements}

The authorsacknowledgethepartial financial supportoftheInternationalAtomic Energy Agency (IAEA), Vienna, the Conselho Nacional de Desenvolvimento Científico e Tecnológico ( $\mathrm{CNPq})$ and Ministério da Ciência e Tecnologia (MCT, Project: Instituto Nacional de Ciência e Tecnologia (INCT) em Metrologia das Radiações na Medicina), Brazil.

\section{References}

[1] Canevaro, L.V. (2009) Revista Brasileira De Medicina, 3, 101-115. http://playmagem.com.br/radiologia/radiologia intervencionosta.PDF

[2] International Eletrotechnical Commission (2003) Medical Electrical Equipment—Dose Area Product Meters. IEC 60580, Geneva.

[3] International Eletrotechnical Commission (1997) Medical Electrical Equipment-Dosimeters With Ionizing Chamber and/or Semi-Conductor Detectors as Used in X Ray Diagnostic Imaging. IEC 61674, Geneva.

[4] International Atomic Energy Agency (2007) Dosimetry in Diagnostic Radiology: An International Code of Practice. IAEA, Vienna (Technical Report Series No. 457).

[5] Corrêa, E.L., Vivolo, V. and Potiens, M.P.A. (2012) Applied Radiation and Isotopes, 70, 1396-1399. http://dx.doi.org/10.1016/j.apradiso.2012.01.012

[6] Franciscatto, P.C. (2009) Caracterização das qualidades de radiação X seguindo as recomendações da norma IEC 61267 no laboratório de calibração do IPEN. Master Thesis, Instituto de Pesquisas Energéticas e Nucleares, Universidade de São Paulo, São Paulo.

[7] International Eletrotechnical Commission (2005) Medical Diagnostic X Ray Equipment—Radiation Conditions for Use in the Determination of Characteristics. IEC 61267, Geneva.

[8] Costa, N.A. and Potiens, M.P.A. (2014) Radiation Physics and Chemistry, 104, 201-203. http://dx.doi.org/10.1016/j.radphyschem.2014.03.004

[9] Bureau International des Poidset Mesures (2008) International Vocabulary of Metrology_Basic and General Concepts and Associated Terms (VIM). BIPM, Sèvres.

[10] Toroi, P., Komppa, T., Kosunen, A. and Tapiovaara, M. (2008) Physics in Medicine and Biology, 53, 5207-5221. http://dx.doi.org/10.1088/0031-9155/53/18/024

[11] Costa, N.A. and Potiens, M.P.A. (2014) Radiation Physics and Chemistry, 95, 214-216. http://dx.doi.org/10.1016/j.radphyschem.2013.07.028

[12] Costa, N.A., Correa, E.L. and Potiens, M.P.A. (2011) Performance Evaluation of a Kerma-Area Meter in the Mammography Radiation Qualities. Proceedings of the International Nuclear Atlantic Conference, Belo Horizonte, 24-28 October 2011.

[13] International Electrotechnical Commission (1994) Medical Diagnostic X-Ray Equipment-Radiation Conditions for Use in the Determination of Characteristics. IEC 1267, Geneva. 